\title{
Retrospective analysis of idiopathic scoliosis medical records coming from one out-patient clinic for compatibility with Scoliosis Research Society criteria for brace treatment studies
}

\author{
Krzysztof Korbel $^{1 *}$, Łukasz Stoliński $^{1}$, Mateusz Kozinoga ${ }^{1,2}$ and Tomasz Kotwicki ${ }^{2}$
}

From 12th International Conference on Conservative Management of Spinal Deformities - SOSORT 2015 Annual Meeting Katowice, Poland. 7-9 May 2015

\begin{abstract}
Background: First author attempted to analyse medical records of patients with idiopathic scoliosis for compliance with the Scoliosis Research Society brace studies criteria. A retrospective analysis of medical records of 2705 girls treated from 1989 to 2002 was carried out.

Methods: Age, Cobb, Risser and menarchal status were analyzed for compliance with the Scoliosis Research Society brace studies criteria: a) age $\geq 10$ years, b) Risser $0-2$, c) $25-40^{\circ}$ Cobb angle, d) no earlier treatment, e) patients before first menses or not more than one year from first menses.

Results: It has been found that 183 girls out of 2705 were $\geq 10$ years old and in the range $25-40^{\circ}$ Cobb angle. One hundred two out of 2705 patients revealed eligible for brace effectiveness study according to SRS 2005 criteria. 120 out of 2705 patients revealed eligible for brace brace effectiveness study according to SRS-SOSORT 2014 criteria.

Conclusion: The excluded patients revealed too old or with too significant Cobb angles. This indicates the changing criteria for scoliosis brace treatment over the time. Direct comparison of current results of brace treatment with historical series of cases turns out to be very difficult.
\end{abstract}

Keywords: Idiopathic scoliosis, SRS criteria, Brace treatment

\section{Background}

The initial idea of the work was to evaluate results of Idiopathic Scoliosis (IS) brace treatment performer at one outpatient clinic in the years 1989-2002. First author attempted to analyse medical records of patients with idiopathic scoliosis for compliance with the Scoliosis Research Society 2005 brace studies criteria. In 2015, the SRS-SOSORT Consensus modified those criteria by excluding the 1-year post-menarche limit as the inclusion criterion [1]. The research on the effectiveness of the

\footnotetext{
* Correspondence: k.korbel@wp.pl

${ }^{1}$ Rehasport Clinic, Górecka 30, Poznan 60-476, Poland

Full list of author information is available at the end of the article
}

brace treatment in IS according to different criteria were carried out. In 1995 Nachemson, Peterson [2] as experts of Scoliosis Research Society presented the results of brace treatment for 286 girls followed through the prospective assessment. The inclusion criteria were: a) female sex, b) diagnosed idiopathic scoliosis, c) bone age between 10-15 years, d) single curvature with apex between 8 th thoracic vertebra and 1 st lumbar vertebra, e) $25-35^{\circ}$ Cobb angle [2]. Also in 1995, Olafsson et al published a retrospective assessment of the effectiveness of Boston brace treatment in 64 patients, 61 girls $(95.3 \%)$ and three boys (4.7\%). The inclusion criteria were: at least one year to growth completion considering the bone maturity and curvature 
progression, b) $25-45^{\circ}$ Cobb angle, c) progression $\geq 5^{\circ}$ confirmed with X-ray performed in the period of 6 months before brace application, d) no previous treatment, e) minimum two years of observation from the moment of stopping of brace application and at least 18 years of age, f) both sexes, g) diagnosed idiopathic scoliosis [3]. In 2003 Landauer et al published the results of retrospective research of the effectiveness of brace treatment in 62 patients complied with inclusion criteria : a) girls, b) rightsided thoracic idiopathic scoliosis, c) $20-40^{\circ}$ Cobb angle, d) brace treatment started in 10-14 years old, e) no first menses, f) minimum two years before expected skeletal maturity [4]. The SRS criteria of effectiveness of SpineCor brace treatment of 2005 in 2007 were applied by Coillard et al [5] for prospective assessment of 493 patients brace treated in the years 1993-2006. Two hundred forty-nine patients $(50 \%)$ complied with complete inclusion criteria, 79 of them (16\%) had not finished the treatment and 170 (34 \%) constituted the final material [5]. In 2011 Zaborowska-Sapeta et al published the results of effectiveness of Cheneau brace according to SOSORT and SRS guidelines of the patients treated in years 2003-2008 from one outpatient clinic. The study was prospective and the inclusion criteria were following: a) both sexes, b) diagnosed idiopathic scoliosis, c) $20-40^{\circ}$ Cobb angle, d) no previous treatment, e) Risser $\geq 4$ at the moment of treatment finishing, f) minimum one year of observation after completion of brace treatment. The inclusion criteria were met by 72 out of 192 patients ( $37.5 \%), 120$ patients (62.5 $\%)$ were excluded due to: a) skeletally immature and during the treatment $=66$ patients, $\mathrm{b}$ ) non-idiopathic form of the disease $=47$ patients. Among 72 patients there were: a) 58 girls (73.4\%), b) 21 boys (26.6\%) [6]. In 2015 Kuroki et al [7] published on retrospectively assessed the effectiveness of OMC brace treatment in 31 patients, 29 girls $(93.5 \%)$ and two boys $(6.5 \%)$ treated in the years 1999 2010. The inclusion criteria were modified SRS criteria: a) diagnosed idiopathic scoliosis, b) age $\geq 10$ years, c) Risser $0-2$, d) patients before first menses or no more than one year from first menses, e) $20-40^{\circ}$ Cobb angle, with at least two years observation after reaching the bone maturity. The authors modified the SRS criteria by Cobb angle parameter from the value $25-40^{\circ}$ to $20-40^{\circ}$ invoking the conformity of Weinstein and the associates $[7,8]$.

\section{The aim of the study}

To find out how many patients treated in one outpatient clinic in the years 1989-2002 for IS with a corrective brace fulfilled the SRS criteria.

\section{Study design}

Retrospective.

\section{Methods}

A retrospective review of the medical records of girls with IS treated in outpatient clinic of Wiktor Dega University Orthopaedic Hospital in Poznan, Poland in years 1989-2002 was carried out. The outpatient clinic's scope was intended for all types of scoliosis. The patients age, Cobb angle, Risser bone maturity and menses status were recorded from medical charts and available X-ray documentation. The medical reports were analysed in compliance with 2005 SRS criteria of the brace treatment results assessment (inclusion criteria): a) age $\geq 10$ years, b) Risser $0-2$, c) $25-40^{\circ}$ Cobb angle, d) no earlier treatment, e) patients before first menses or not more than one year from first menses. Exclusion criteria: a) $<10$ years, b) Risser $>2$, c) $<25^{\circ}$ or $>40^{\circ}$ Cobb angle, d) patients treated earlier, e) patients with first menses $>1$ year, f) non-idiopathic form of disease [9].

\section{Results and discussion}

The total number of analysed medical records amounted to 2705 . The study included only girls. It has been found that 183 girls out of 2705 (6.8\% of the total treated with a brace) were $\geq 10$ years old and in the range $25-40^{\circ} \mathrm{Cobb}$ angle. However, considering the status of maturation, the number of girls complying with complete SRS criteria amounted to 102 out of 183 (3.8\% of total of the treated): 42 girls with single thoracic curvature, 60 girls with double thoracic and lumbar curvature. The reasons of excluding 81 girls from analysis were: a) first menses $>1$ year $=18$ patients, b) Risser $>2=24$ patients, $\mathrm{c}$ ) first menses $>1$ year and Risser $>2=39$ patients. In the final group of 102 girls the mean age at first visit was $12.6 \pm 1.7$ years, the mean age at the moment of beginning of brace treatment was $12.9 \pm$ 1.7 years.

If the study followed SRS-SOSORT 2015 criteria [1], the study would include 120 girls. Excluded patients show Table 1.

Table 1 Table showing the characteristics of the included subjects not respecting the SRS/SOSORT criteria

\begin{tabular}{llllll}
\hline Localisation & Amount & Cobb angle & Risser & Menarchal & Age \\
\hline TH & 11 & $30,9 \pm 5,1$ & $3,9 \pm 0,8$ & 0 & 14 y $5 \mathrm{~m} \pm 1,4$ \\
TH/LS & 13 & $30,2 \pm 5,0$ & $3,8 \pm 0,8$ & 0 & 13 y $9 \mathrm{~m} \pm 1,3$ \\
TH & 11 & $32,2 \pm 5,0$ & $4,7 \pm 0,5$ & 11 & 15 y $6 \mathrm{~m} \pm 1,2$ \\
TH/LS & 28 & $31,9 \pm 4,0$ & $4,2 \pm 0,8$ & 28 & 15 y $0 \mathrm{~m} \pm 1,7$ \\
\hline
\end{tabular}




\section{Conclusions}

The review of literature in range of using by authors the criteria for assessment of effectiveness of IS brace treatment shows diversity and variability. In inclusion criteria the following were considered: a) different values of Cobb angle, b) different biological maturity, c) different age, d) different location of curvature, e) different sexes. The retrospective analysis of SI medical documentation from outpatient clinic in Poznan from the years 19892002 showed that girls brace treated in majority were older, more matured and presented a bigger Cobb angle in comparison with current SRS criteria of brace treatment studies. If the study followed SRS-SOSORT 2015 criteria [1], the study would include 120 girls. The above analysis confirms the changing criteria applied in noninvasive SI treatment. Considering the fact that brace treatment coincides with most difficult age for a young man which is adolescence as well as specificity of brace treatment $23 \mathrm{~h} / 24 \mathrm{~h}$, and aesthetic discomfort connected with a brace itself, one should agree that the research should be further carried out aiming at determination of factors decisive in result of IS brace treatment, based on IS natural history. Continuous observations and analysis compared to development acceleration will help to determine the most optimal conditions of SI brace treatment. Direct comparison of current results of brace treatment with historical series of cases turns out to be very difficult.

\section{Declarations}

This article has been published as part of Scoliosis and Spinal Disorders Volume 11 Supplement 2, 2016. Research into Conservative Management of Spinal Deformities: Short Articles from the SOSORT 2015 Meeting. The full contents of the supplement are available online http://scoliosisjournal.biomedcentral.com/articles/supplements/volume-11supplement-2.

\section{Availability of data and materials}

Retrospective analyse medical records of patients from clinic of Wiktor Dega University Orthopaedic Hospital in Poznan.

\section{Authors' contribution}

KK- Project research, collected data base and main author of the text. KM-collected references. St-collected refernces. KT- supervisor of the paper. All authors read and approved the final manuscript.

\section{Competing interests}

The authors declare that they have no competing interests.

\section{Consent for publication}

Not applicable.

\section{Ethics approval and consent to participate}

Consent of the ethics committee Poznan University of Medical Sciences number 83/11. Consent to participate not applicable.

\section{Author details}

${ }_{1}^{1}$ Rehasport Clinic, Górecka 30, Poznan 60-476, Poland. ${ }^{2}$ Spine Disorders and Pediatric Orthopaedics Department, University of Medical Sciences, Górecka 30, Poznan 60-476, Poland.

Published: 14 October 2016

\section{References}

1. Negrini S, Hresko T, O'Brien J, Price N. SOSORT Boards and SRS NonOperative Committee: Recommendations for research studies on treatment of idiopathic scoliosis: Consensus 2014 between SOSORT and SRS nonoperative management committee. Scoliosis. 2015;10:8.

2. Nachemson A, Peterson L. Effectiveness of treatment with a brace in girls who have Adolescent Idiopathic Scoliosis. J Bone Joint Surg. 1995;77-A:815-22.

3. Olafsson Y, Saraste H, Söderlund V, Hoffsten M. Boston Brace in the Treatment of Idiopathic Scoliosis. J Pediatr Orthop. 1995;15:524-7.

4. Landauer F, Wimmer C, Behensky H. Estimating the final outcome of brace treatment for idiopathic thoracic scoliosis at 6-month follow-up. Pediatric Rehabilitation. 2003;6(3-4):201-7.

5. Coillard C, Vachon V, Circo A, Beaséjour M, Rivard C. Effectiveness of the SpineCor Brace Based on the New Standarized Criteria Proposed by the Scoliosis Research Society for Adolescent Idiopathic Scoliosis. J Pediatr Orthop. 2007;27:375-9.

6. Sapeta-Zaborowska K, Kowalski I, Kotwicki T, Protasiewicz-Fałdowska H, Kiebzak W. Effectiveness of Chêneau brace treatment for idiopathic scoliosis: prospective study in 79 patients followed to skeletal maturity. Scoliosis. 2011;6:2.

7. Kuroki H, Inomata N, Hanamaka H, Higa H, Chosa E, Tajima N. Predictive factors of Osaka Medical College (OMC) brace treatment in patients with adolescent idiopathic scoliosis. Scoliosis. 2015;10:11.

8. Weinstein SL, Dolan LA, Wright JG, Dobbs MB. Design of the bracing in adolescent idiopathic trial (BrAIST). Spine. 2013;38:1832-41.

9. Richards SB, Bernstein R, D'Amato C, Thompson G. Standarization of criteria for Adolescent Idiopathic Scoliosis brace studies. Spine. 2005;30:2068-75.

Submit your next manuscript to BioMed Central and we will help you at every step:

- We accept pre-submission inquiries

- Our selector tool helps you to find the most relevant journal

- We provide round the clock customer support

- Convenient online submission

- Thorough peer review

- Inclusion in PubMed and all major indexing services

- Maximum visibility for your research

Submit your manuscript at www.biomedcentral.com/submit
) Biomed Central 